\title{
LA TUTELA JURISDICCIONAL DEL ACREEDOR
}

\author{
Fernando Vidal Ramírez*
}

\begin{abstract}
Resumen
El acreedor tiene como derecho fundamental el derecho a ser pagado. El artículo $1219^{\circ}$ del Código Civil legisla como efecto de las obligaciones, el derecho del acreedor a la tutela jurisdiccional si el deudor no las cumple.

El presente estudio está dedicado a la interpretación del acotado artículo $1219^{\circ}$, en cuanto autoriza el accionar del acreedor para hacer efectiva la tutela jurisdiccional frente al incumplimiento de su deudor.

Palabras clave: Incumplimiento de la obligación - acreedor - deudor indemnización.
\end{abstract}

\begin{abstract}
The creditor has like a fundamental right, the right to be paid. Art. $1219^{\circ}$ of the Civil Code legislates as an effect of the obligations, the right of the creditor to the jurisdictional trusteeship if the indebted one does not fulfill them.

The present study is dedicated to the interpretation of the mentioned Art. $1219^{\circ}$ as it authorizes the creditor to make the jurisdictional trusteeship effective against his indebted one.

Key words: Breach of the obligation - lender - indebted - indemnification.

\section{Sumario}

1. Antecedentes. 2. El incumplimiento del deudor como presupuesto de la tutela jurisdiccional del acreedor. 3 . La tutela jurisdiccional del acreedor.
\end{abstract}

\footnotetext{
* Doctor en Derecho. Profesor de la Pontificia Universidad Católica del Perú. Miembro del Consejo Consultivo
} del Poder Judicial de Perú. 


\section{ANTECEDENTES}

El acreedor, históricamente, ha sido siempre la parte fuerte de la relación jurídico-obligacional, desdelos tiempos primitivos hasta que losordenamientos jurídicos le fueron dando una protección relativa al deudor.

En el antiguo Derecho Romano, la obligatio generaba un vínculo que sujetaba de manera indesligable a la persona del debitor o deudor a su accipiens o acreedor y era el deudor, con su persona, el que respondía por sus obligaciones. Si el deudor no cumplía el acreedor podía someterlo a las penas corporales más rudas, a su mutilación y hasta someterlo a la esclavitud.

La obligatio generaba, un derecho sobre la persona del deudor, un ius in personam, que, a su vez, generaba una actio in personam, siendo este el origen de la denominación de derecho personal y de acción personal, que es la denominación que, a pesar de su evolución respecto a la responsabilidad personal del deudor, es la que receptó la codificación civil desde su iniciación a fines del siglo $\mathrm{XVIII}{ }^{1}$.

Pero el rigor del primitivo Derecho Romano se fue atenuand y el nexo personal que unía al debitor con su accipiens se fue debilitando en la medida que la responsabilidad generada por las obligaciones fue evolucionando y dejando de ser una responsabilidad personal para devenir en una responsabilidad patrimonial, según la cual el debitor ya no respondía con su persona sino sólo con sus bienes, como resultado de una progresiva y constante suavización de la condición del obligatus. Fue así como la persona fue dejando de ser el objeto de la ejecución forzada como consecuencia del incumplimiento de la obligación.

Como se sabe la tricotomìa de las obligaciones que determina que sus prestaciones sean de dar, de hacer o de no hacer, tuvo su origen en Roma. $Y$ ya, definida la responsabilidad patrimonial del debitor por obra del Pretor, la ejecución forzada por incumplimiento de la prestación de dar se dirigía para que el debitor la satisfaciera in natura y, posteriormente, por el valor de la cosa que debía entregar. $Y$ no pudiéndose ya constreñir al deudor por las prestaciones de facere o de non facere respondía pecuniariamente.

El Derecho Romano desarrolló, además, toda una temática para la imputación del deudor por la inejecución de sus obligaciones, basándola en el dolo, dolus, y en la culpa, con la graduación en culpa lata y culpa levis, o en la mora por el retardo en el cumplimiento. Dentro de la misma temática desarrolló el casus, 
el caso fortuito o la fuerza mayor, como eximente de la responsabilidad por el incumplimiento.

La ejecución forzada de las obligaciones dio lugar a una diversidad de acciones, actiones, algunas de las cuales han pervivido y llegado hasta nuestros días.

Con estos antecedentes romanistas es como la codificación civil, a partir del Código Francés de 1804, ha planteado como efecto de las obligaciones el derecho del acreedor a hacer uso de las medidas legales para la obtención de las prestaciones incumplidas por el deudor o su cumplimiento in natura, por equivalencia o por otro, sin perjuicio de la indemnización de daños y perjuicios a que hubiera lugar.

La codificación civil peruana ha receptado los conceptos romanistas. El Código Civil de 1852 lo hizo en cuanto al dolo (Artículo 1238 ), la culpa (Artículo $1266^{\circ}$ ) en su graduación de lata y culpa leve y aún levísima (Artículo $1267^{\circ}$ ) pero más como una advertencia al deudor que ofreciéndole tutela jurídica al acreedor (Artículo $1265^{\circ}$ ).

Con algunas modificaciones, el Código Civil de 1936 mantuvo los indicados conceptos del Código antecedente, pero la tutela jurisdiccional al acreedor la planteó de manera explícita y como efecto de las obligaciones (Artículo $1233^{\circ}$ ), siendo el antecedente de esta norma el artículo $1414^{\circ}$ del Proyecto de Código Civil de 1890 y la ponencia de Manuel Augusto Olaechea a la Comisión Reformadora del Código Civil de 1852².

Al plantearse la reforma del Código Civil de 1936, concurrieron las ponencias de Jorge Vega García y de Felipe Osterling Parodi, así como y el Proyecto de la Comisión Revisora ${ }^{3}$, para concluir en la norma contenida en el artículo $1219^{\circ}$, vigente desde el 14 de noviembre de 1984:

“Es efecto de las obligaciones autorizar al acreedor para lo siguiente:

1. Emplear las medidas legales a fin de que el deudor le procure aquello a que está obligado.

2. Procurarse la prestación, o hacérsela procurar por otro, a costa del deudor.

3. Obtener del deudor la indemnización correspondiente.

4. Ejercer los derechos del deudor, sea en vía de acción o para asumir su defensa, con excepción de los que sean inherentes a la persona o cuando lo prohíba la ley. El acreedor para el ejercicio de los derechos mencionados 
en este inciso, no necesita recabar previamente autorización judicial, pero deberá hacer citar a su deudor en el juicio que promueva.

Es posible ejercitar simultáneamente los derechos previstos en este artículo, salvo los casos de los incisos 1) y 2)".

\section{EL INCUM PLIMIENTO DEL DEUDOR COMO PRESUPUESTO DE LA TUTELA JURISDICCIONAL DEL ACREEDOR}

El artículo $1219^{\circ}$, anteriormente transcrito, ha plasmado de manera general los medios por los cuales el acreedor puede hacer efectiva la tutela jurisdiccional a la que tiene derecho, siendo obvio que, para su ejercicio se requiera del incumplimiento del deudor.

El Código Civil se ha ocupado del incumplimiento del deudor y ha desarrollado su tratamiento con las normas de la inejecución de las obligaciones, que vienen a ser también las de la responsabilidad contractual. En el desarrollo de su régimen legal ha previsto la obligación de indemnizar al acreedor por los daños y perjuicios que le generen el incumplimiento, determinando la responsabilidad del deudor por dolo o culpa, pero eximiéndolo cuando el incumplimiento es por caso fortuito o por fuerza mayor, o por causa que no le es imputable, salvo que el deudor haya sido constituido en mora. De este modo, el retardo en el cumplimiento de la obligación que determina la mora o el incumplimiento por dolo o por culpa del deudor, vienen a ser los presupuestos de la tutela jurisdiccional del acreedor.

\subsection{El retardo en el cumplimiento}

La obligación debe ser cumplida en la oportunidad convenida con el acreedor. El artículo $1240^{\circ}$ del Código Civil establece que si no hubiese plazo pactado para el cumplimiento de la obligación el acreedor puede exigir el pago inmediatamente después de contraída. De este modo, el retardo en el cumplimiento de la obligación se configura si el deudor no la cumple inmediatamente después de contraída o si se hubiera pactado un plazo, al vencimiento del plazo.

El plazo, como se sabe, puede estar previsto en una norma legal, que opera preceptivamente o de manera supletoria, por lo que sólo a su vencimiento la obligación es exigible por el acreedor. Puede también ser consecuencia de una resolución jurisdiccional que ordena el cumplimiento de una obligación en un plazo determinado. 
Pero el plazo puede ser también convencional y el Código Civil lo trata como una modalidad del acto jurídico determinada por un hecho futuro y cierto de necesaria realización, y por eso, indesligablemente vinculado al transcurso del tiempo, y por tanto, susceptible de quedar fijado por una fecha anteladamente determinada en el pacto entre acreedor y deudor.

En el acto constitutivo de la obligación, puede no haberse señalado explícitamente un plazo para su cumplimiento, por lo que el artículo $182^{\circ}$ permite que jurisdiccionalmente se establezca su existencia y se fije su duración, a cuyo vencimiento recién será exigible la obligación. Si el plazo ha sido pactado pero sin fijarse su duración y su determinación ha quedado a voluntad del deudor o de un tercero, la duración es también fijada jurisdiccionalmente mediante proceso de trámite sumarísimo, como lo dispone el mismo artículo $182^{\circ}$.

El plazo puede pactarse como plazo suspensivo o resolutorio, aunque debemos advertir que tratándose de un plazo para el cumplimiento de la obligación, el plazo a pactarse es un plazo suspensivo, que también permite al acreedor emplear los medios que considere conducentes a la cautela de su derecho, conforme a lo previsto en el artículo $178^{\circ}$.

El plazo se presume que ha sido pactado en beneficio del deudor, conforme a lo establecido en el artículo $179^{\circ}$, quien puede perder este beneficio por las causales de caducidad previstas en el artículo $181^{\circ}$.

La obligación puede también ser contraída bajo condición suspensiva que, al contrario que el plazo, es un hecho futuro pero incierto, en cuyo caso, el acreedor puede realizar actos conservatorios conducentes a la protección de su derecho, por así permitirlo el artículo $173^{\circ}$ y, de verificarse la realización del hecho, la obligación será exigible.

La llegada de la oportunidad del cumplimiento de la obligación marca el momento en el que, si no es cumplida, se produce su retardo. Pero no sólo la falta de cumplimiento en la oportunidad correspondiente produce el retardo sino también cuando el cumplimiento de la obligación es parcial, pues como precisa el artículo $1220^{\circ}$ del Código Civil, sólo puede entenderse efectuado el pago o cumplimiento cuando se ha ejecutado íntegramente la prestación en que consiste la obligación. El artículo $1221^{\circ}$ lo complementa en cuanto dispone que no puede compelerse al acreedor a recibir parcialmente la prestación, a menos que la ley o el contrato lo autoricen, y que sin embargo, si la deuda tiene una parte líquida y otra ilíquida, puede exigir el acreedor el pago de la primera sin esperar que se liquide la segunda, la que agregamos nosotros, puede dar lugar al empleo por el acreedor de los medios legales a que se refiere el artículo $1219^{\circ}$. 
El cumplimiento parcial de la obligación, como lo es también el cumplimiento defectuoso, pueden asimilarse al retardo en el cumplimiento, y el retardo imputable al deudor lo coloca o puede llevarlo a situación de mora.

La mora viene a ser entonces, una situación de derecho en la que se coloca al deudor por el hecho de haber incurrido en retardo en el cumplimiento de su obligación, ya sea porque está prevista en la ley o pactada en el contrato y opera automáticamente (mora ex re), conforme a las causales previstas en el artículo $1333^{\circ}$ del Código Civil ${ }^{4}$, o porque el deudor ha sido intimado al cumplimiento de la obligación y no ha cumplido (mora ex personae). La intimación puede ser planteada por el acreedor, judicial o extrajudicialmente y constituye ya el empleo de una medida legal para que el deudor cumpla con la prestación a que está obligado.

El deudor constituido en mora, conforme a lo dispuesto por el artículo $1336^{\circ}$ del Código Civil, responde por los daños y perjuicios que irrogue por el retraso en el cumplimiento de la obligación y por la imposibilidad sobreviniente, aun cuando ella obedezca a causas que no le sea imputable, aunque puede sustraerse a esta responsabilidad probando que ha incurrido en el retraso sin culpa, o que la causa no imputable habría afectado la prestación aún si la hubiera cumplido oportunamente.

\subsection{El incumplimiento doloso}

El incumplimiento es doloso cuando el deudor tiene el designio de inejecutar la obligación. Según el artículo $1318^{\circ}$ del Código Civil, procede con dolo quien deliberadamente no ejecuta la obligación. De este modo, el dolo queda conceptuado en su acepción de intencionalidad, quedando trazada la diferencia con el dolo en su acepción de engaño o medio de inducción a error.

El dolo se manifiesta en una acción o en una omisión. El dolo por acción se configura en el incumplimiento deliberado de una obligación de no hacer, mientras que el dolo por omisión se configura en el incumplimiento de una obligación de dar o en una obligación de hacer.

El incumplimiento doloso obliga al deudor a indemnizar al acreedor, conforme a lo dispuesto por el artículo $1321^{\circ}$, comprendiendo el resarcimiento por la inejecución de la obligación o por su cumplimiento parcial, tardío o defectuoso, tanto el daño emergente como el lucro cesante en cuanto sean consecuencia inmediata y directa del incumplimiento. Puede comprender también el daño moral conforme al artículo $1322^{\circ}$. 
El acreedor perjudicado por el incumplimiento, si le imputa dolo al deudor, debe probarlo, por así disponerlo el artículo $1330^{\circ}$ del Código Civil.

\subsection{El incumplimiento culposo}

El incumplimiento es culposo cuando el deudor no tiene el propósito de inejecutar la obligación, pero la inejecuta por negligencia. La culpa, como el dolo, son elementos subjetivos que determinan la responsabilidad del deudor. El Código Civil gradúa la culpa, distinguiéndola en culpa inexcusable y en culpa leve.

La culpa inexcusable linda con el dolo. El artículo $1319^{\circ}$ la conceptúa como una negligencia grave y la responsabilidad del deudor la equipara al incumplimiento doloso, pues el artículo $1321^{\circ}$ lo obliga también a indemnizar al acreed or, com prendiendo el resarcimiento por la inejecución de la obligación o por su cumplimiento parcial, tardío o defectuoso, tanto el daño emergente como el lucro cesante en cuanto sean consecuencia inmediata y directa del incumplimiento. Puede comprender también el daño moral, previsto en el artículo $1322^{\circ}$.

El acreedor perjudicado por el incumplimiento, si le imputa culpa inexcusable al deudor, debe probarla, por así disponerlo el artículo $1330^{\circ}$ del Código Civil.

La culpa leve es considerada un atenuante en la responsabilidad del deudor. El artículo $1320^{\circ}$ la conceptúa como la omisión de la diligencia ordinaria exigida por la naturaleza de la obligación y las circunstancias que corresponden a la persona del deudor, en función del tiempo y del lugar. En este caso, conforme al acotado artículo $1321^{\circ}$, en su segundo párrafo, si bien el deudor queda sujeto a la obligación de indemnizar al acreedor, el resarcimiento se limita al daño que podía preverse al tiempo en que la obligación fue contraída. Consideramos que no comprende el daño moral.

La culpa leve no requiere del onus probandi. La puede alegar el deudor y corresponde al órgano jurisdiccional calificarla.

\section{LA TUTELA JURISDICCIONAL DEL ACREEDOR}

Establecidos los presupuestos de la tutela jurisdiccional, el acreedor puede acceder a ella mediante las medidas que le ofrece el artículo $1219^{\circ}$ del Código Civil, que como ya hemos indicado, no comprende todos los mecanismos que el ordenamiento jurídico ha previsto para que ejercite su derecho a alcanzar una tutela jurisdiccional efectiva. 
Es oportuno advertir que los medios legales que el artículo $1219^{\circ}$ pone al alcance del acreedor están referidos al acreedor quirografario, esto es, del acreedor que no tiene asegurado su crédito mediante una garantía real. El acreedor prendario, hipotecario o anticrético puede ejecutar directamente el bien afectadoen garantía ejercitando los derechos persecutorios y preferentes de los que goza.

El acreedor quirografario o común, frente al incumplimiento de su deudor, no tiene privilegios y sólo puede actuar mediante las vías procesales que el ordenamiento jurídico pone a su alcance para la satisfacción de su derecho creditorio.

Planteada la situación del acreedor quirograrario es conveniente diferenciar la tutela jurídica de la tutela jurisdiccional. La tutela jurídica se la ofrece el ordenamiento jurídico al acreedor mediante la constitución en mora del deudor si la ha pactado como mora automática, o si requiere de la intimación, la que le plantee extrajudicialmente, pues la que plantee judicialmente es ya el empleo de un medio legal que de manera directa lo hace acceder a la tutela jurisdiccional. Le ofrece también la inserción de una cláusula penal en el contrato que genera las obligaciones para el deudor, así como el reconocimiento de la facultad de resolver extrajudicialmente el contrato, entre otros medios.

La tutela jurisdiccional se la ofrece el ordenamiento jurídico al acreedor para que inste a su deudor como efecto de la obligación que ha incumplido, por lo que vamos a detenernos en cada uno de los incisos del artículo $1219^{\circ}$.

\subsection{Los medios legales a fin de que el deudor le procure al acreedor aquello a que está obligado}

El artículo $1219^{\circ}$ inciso 1), le otorga al acreedor, de modo general y mediante la denominada acción personal, los medios legales a fin de que su deudor le procure aquello a que está obligado y llegar por esos medios a la ejecución forzada de la obligación. Se trata, entonces, de una acción de cumplimiento de la prestación en que la obligación consiste, sea de dar, de hacer o de no hacer. Pero no es así en relación a los caracteres que pueden revestir las obligaciones.

Si la obligación es de dar, hay que considerar la naturaleza y características del bien cuya entrega constituye la prestación, pues debe tratarse de un bien cierto ya que, si es un bien incierto debe ser indicado por su especie y cantidad. Si se trata de un bien fungible, como dinero u otros bienes que pueden contarse, medirse o pesarse, o de bienes no consumibles, el empleo de los me- 
dios legales determinará que el deudor le procure la entrega porque el cumplimiento del dare es físicamente posible. Pero si se trata de bienes no fungibles, consumibles o que han perecido, no existe la posibilidad de su entrega por el deudor, en cuyo caso el cumplimiento del dare será por equivalencia.

Si la obligación es de hacer, el deudor puede ser forzado a cumplirla, a no ser que para ello deba emplearse violencia contra su persona, en cuyo caso el acreedor tendrá que pedir que la prestación la realice un tercero o la propia autoridad jurisdiccional ante la renuencia del obligado. Y, si la obligación de hacer tiene carácter personalísimo, esto es, que ha sido contraída intuito personae, el cumplimiento del facere será por equivalencia.

Por último, si la obligación es de no hacer el acreedor podrá exigir la ejecución forzada y destruir lo ejecutado por cuenta del deudor, quedando cumplido el non facere, pues en caso contrario el cumplimiento del non facere será también por equivalencia.

La referencia al cumplimiento por equivalencia requiere de una precisión, pues consideramos no debe confundirse con la indemnización de daños y perjuicios, pese al criterio contrario expresado por León Barandiarán en su comentario al inciso 2) del artículo $1233^{\circ}$ del Código Civil de $1936^{5}$ y el criterio mayoritario de la doctrina nacional. El cumplimiento por equivalencia es un modo subsidiario de cumplimiento que consiste en el abono de una suma de dinero que represente el valor de la prestación originaria no cumplida y que por el incumplimiento, cualquiera que sea su naturaleza, se transforma en una prestación dineraria. Nuestro Código Civil no hace mención al cumplimiento por equivalencia y ello ha generado la confusión con la indemnización, la que en nuestra opinión, puede acumularse a la prestación dineraria equivalente a la prestación no cumplida si con el incumplimiento se han generado daños y perjuicios, los cuales son además, resarcibles.

El empleo de los medios legales para hacer exigible la obligación, mediante la tutela jurisdiccional, es la acción genérica con la que el acreedor puede acudir a la jurisdicción, utilizando los procedimientos establecidos por el Código Procesal Civil y llegar así a la ejecución forzada de la obligación, con las limitaciones que han sido expuestas.

Los medios legales así denominados por el inciso 1) del artículo $1219^{\circ}$ del Código Civil se resumen, entonces, en la acción personal a la que se refiere el Código Civil de manera genérica y a la que nosotros preferimos denominar acción creditoria. 
Ahora bien, analizada, en su generalidad, la facultad de emplear los medios legales, vamos a ocuparnos, específicamente, de otros medios con los que el acreedor puede acudir a la jurisdicción, esto es, de otras acciones que puede incoar en protección de su derecho crediticio, a las que se les conoce con un nomen iuris propio y no quedan comprendidas en el ámbito de la denominada acción personal, que nosotros, repetimos, preferimos denominar creditoria.

En primer lugar, la acción fraudatoria, que es la conocida en la doctrina como acción pauliana y queel Código Civil equivocadamente llama acción revocatoria, pese a que la legisla como una acción de ineficacia. El acreedor la entabla para que se declare la ineficacia de los actos de disposición o de gravamen realizados por el deudor y que el acreedor califica de fraudulentos. Probado el fraude y declarada la ineficacia, los bienes dispuestos o gravados por el deudor fraudator reingresan a su esfera jurídica o quedan desafectados y el acreedor puede proceder a la ejecución forzada de la obligación sobre esos bienes, salvo que hayan sido adquiridos por terceros de buena fe y a título oneroso ${ }^{6}$.

En segundo lugar, la acción de nulidad por simulación. El acreedor puede incoarla impugnando la validez del acto jurídico o el contrato que considera que su deudor ha celebrado simuladamente con la finalidad de engañarlo y generarle perjuicio. Puede incoarse por causa de simulación absoluta o de simulación relativa. Probada la simulación y declarada la nulidad del acto jurídico o del contrato, los bienes simuladamente dispuestos continúan en la esfera jurídica del deudor, de la que nunca salieron o las obligaciones simuladamente contraídas devienen en inexistentes, pudiendo el acreedor proceder a la ejecución forzada sobre los bienes simuladamente dispuestos, salvo que hayan sido adquiridos por terceros de buena fe y a título oneroso; y de ser el caso, proceder a la ejecución forzada del deudor excluyendo a los simulantes acreedores?.

Adicionalmente, pueden considerarse las acciones cambiarias generadas por el incumplimiento de las obligaciones cambiarias reguladas en la Ley de Títulos Valores, como son la acción directa, que es la que ejercita el tenedor del título contra el obligado principal y su avalista, así como contra otros garantes de la obligación si han constituido garantías reales; la acción de regreso, que es la que ejercita el tenedor del título contra los obligados solidarios y/o sus garantes; la acción de ulterior regreso, que es la que puede ejercitar el tenedor del título que ha satisfecho la obligación representada en él contra los obligados y/o garantes anteriores; la acción de repetición del garante que tuvo que satisfacer la obligación contra el obligado principal; y la acción causal, cuando se ha extinguido la acción cambiaria8. 
Por último, el acreedor tiene la gama de medidas cautelares que le ofrece el Código Procesal Civil y que puede solicitar a los órganos jurisdiccionales.

Como advierte el último párrafo de la norma sub examine el empleo de estas medidas legales, dirigidas a que el deudor cumpla con la prestación a que está obligado, excluyen la posibilidad de que el acreedor pretenda procurársela por otro.

\subsection{Procurarse la prestación o hacérsela procurar por otro a costa del deudor}

El artículo $1219^{\circ}$ inciso 2) del Código Civil faculta al acreedor a procurarse la prestación o hacérsela procurar por otro, a costa del deudor. La norma plantea una facultad alternativa: el acreedor se procura la prestación o se la hace procurar por otro.

La facultad dirigida a "procurarse la prestación" es redundante, pues ella implica que el acreedor proceda a emplear los medios legales que hemos expuesto anteriormente, por lo que, por su redundancia, resulta ociosa, máxime si se toma en consideración que el inciso 2) del acotado artículo $1219^{\circ}$ registra como antecedente el inciso 2) del artículo $1233^{\circ}$ del Código de 1936 que sólo facultaba al acreedor a procurarse la prestación por otro.

Procurarse la prestación por otro, esto es, el cumplimiento de la obligación por persona distinta al deudor, es absolutamente viable y tiene previsión explícita en el artículo $1122^{\circ}$ del Código Civil, según el cual puede hacer el pago cualquier persona, tenga o no interés en el cumplimiento de la obligación, sea con el asentimiento del deudor o sin él, salvo que el pacto o su naturaleza lo impidan.

Como puede inferirse entonces, si la obligación es de dar y se trata de un bien cierto o de un bien incierto pero indicado por su especie y calidad, nada obsta su entrega por un tercero para dar cumplimiento al dare.

Si se trata de una obligación de hacer, que no tiene carácter personalísimo, la prestación puede ser ejecutada por persona distinta al deudor, quedando cumplido el facere.

Si se trata de una obligación de no hacer, la destrucción de lo hecho por el deudor puede hacerla un tercero, quedando cumplido el non facere. 
En cualquiera de los casos expuestos y conforme al inciso 2) del acotado artículo $1219^{\circ}$, la procuración de la prestación por un tercero es a costa del deudor.

La procuración del cumplimiento de la prestación por otro, como lo advierte el último párrafo de la norma sub examine, excluye la posibilidad de que el acreedor pueda ya dirigirse directamente contra el deudor.

\subsection{Obtener del deudor la indemnización correspondiente}

El artículo $1219^{\circ}$ inciso 3), faculta al acreedor a obtener de su deudor la indemnización por los daños y perjuicios que pueda haberle irrogado con el incumplimiento de la obligación. Ya al ocuparnos de los presupuestos de la tutela jurisdiccional al acreedor nos hemos referido al incumplimiento doloso o culposo del deudor, así como a su constitución en mora, y hemos citado el artículo $1321^{\circ}$ del Código Civil que regula la indemnización de daños y perjuicios según se haya producido por dolo del deudor o por su culpa, sea inexcusable o leve.

Los factores determinantes de la indemnización son los daños y perjuicios irrogados al acreedor por el incumplimiento de la obligación por su deudor, los cuales deben ser resarcidos. Ya hemos dejado expuesta nuestra opinión en el sentido de que la indemnización no viene a ser el cumplimiento por equivalencia de la obligación y que, por tanto, la indemnización puede acumularse a la pretensión del acreedor, de resarcirse de los daños y perjuicios que se le han irrogado.

La indemnización comprende las pérdidas generadas por el incumplimiento y las ganancias dejadas de percibir por el acreedor, todo lo cual cae dentro del concepto genérico de daño. Sin embargo, la codificación civil ha trazado la distinción del daño, daño emergens, del perjuicio, lucrum cesans. La distinción implica, entonces, que puede haber un daño actual o cierto, si se ha producido ya, que es el damnum emergens, o un daño potencial o futuro, que está por producirse, que es el lucrum cesans. Ambos, desde luego, son resarcibles y deben quedar comprendidos en la indemnización.

La pretensión de resarcimiento de los daños y perjuicios supone el ejercicio de una acción indemnizatoria, ejercitable en todos los casos en que haya lugar a una pretensión resarcitoria, sea por imputarse responsabilidad contractual, que es el caso de la inejecución de una obligación generada por un contrato o mas genéricamente aún, por un vínculo jurídico que le da a una de las 
partes el carácter de acreedor y a la otra la de deudor, o por imputación de responsabilidad extracontractual, cuando el pretensor de la indemnización no ha estado previamente vinculado al obligado a la indemnización y el vínculo lo genera el hecho indemnizable y que, por tanto, da lugar a una amplia gama de posibilidades para accionar.

La acción indemnizatoria por inejecución de obligaciones, o por su cumplimiento parcial, tardío o defectuoso, dentro del marco de la responsabilidad contractual, conlleva la carga de la prueba al acreedor, que no sólo tendrá que probar el dolo o la culpa inexcusable, sino también la cuantía de los daños y perjuicios, conforme lo dispone el artículo $1331^{\circ}$ del Código Civil. Sin embargo, si la obligación incumplida es dineraria, conforme al artículo $1324^{\circ}$, el resarcimiento es mediante los intereses moratorios que se devengan automáticamente, sin que el acreedor deba probar haber sufrido daño, salvo que se hubiere pactado una indemnización por el daño ulterior, vale decir, una cláusula penal, en cuyo caso el acreedor si tiene que probar el daño sufrido.

El último párrafo del artículo $1219^{\circ}$ abre la posibilidad que, además del empleo de los medios legales a que se refiere el inciso 1) y a la procuración de la prestación por persona distinta al deudor, el acreedor pueda ejercitar la acción indemnizatoria.

\subsection{Ejercer los derechos del deudor, sea en vía de acción o para asumi r su defensa}

El artículo $1219^{\circ}$ inciso 4), faculta al acreedor a ejercer los derechos de su deudor, sea en vía de acción o para asumir su defensa, con excepción de los que sean inherentes a su persona o cuando lo prohíba la ley. Agrega que el acreedor para el ejercicio de los derechos de su deudor no necesita recabar previamente autorización judicial, pero deberá citar al deudor en el juicio que promueva.

Como puede apreciarse, la norma otorga al acreedor una doble facultad: una, para ejercer los derechos de su deudor en vía de acción $\mathrm{y}$, otra, para asumir la defensa de su deudor. Ambas, con la finalidad de que el acreedor pueda hacerse pago con aquello que su deudor no pretende porque no lo exige o con aquello que es pretensión de otro acreedor sobre el deudor y éste permanece inerte. En ambos casos el medio que emplea el acreedor para hacerse pago es la acción subrogatoria, de vieja raigambre romanista y civilista. 
Se le llama acción subrogatoria en razón de que el acreedor se sustituye en los derechos de su deudor y los ejercita, ya sea para dirigirse contra un deudor de su deudor a fin de que mediante la ejecución forzada obtener la satisfacción de su crédito, o para oponerse a las pretensiones de un acreedor de su deudor a fin de preservar los bienes de su patrimonio con los que él pretende hacerse pago.

Como el acreedor que puede ejercitar la acción subrogatoria es un acreedor quirografario, la integración de bienes al patrimonio de su deudor como la defensa de los bienes de su deudor, el resultado de la acción subrogatoria no le otorga ningún privilegio, por lo que pueden concurrir con el acreedor que instó subrogatoriamente los demás acreedores.

El ejercicio de la acción subrogatoria ha pasad o prácticamente desaparecido en nuestro medio y la norma que pretende darle sustento ha sido criticada desde la perspectiva del Derecho Procesal ${ }^{9}$. Sin embargo, el Código Procesal Civil la complementa con la figura de la sustitución procesal y de la intervención del acreedor en un proceso en el que no es parte sino su deudor.

En efecto, el artículo $60^{\circ}$, con la figura de la sustitución procesal, en concordancia con la norma sub examine, faculta al acreedor a iniciar un proceso o coadyuvar la defensa del ya iniciado por el interés que tenga en su resultado. Esta intervención está además regulada en los artículos $97^{\circ}$ y $98^{\circ}$, según se trate de una simple intervención coadyuvante o de una intervención litisconsorcial.

\footnotetext{
Vide, del autor. En torno a las acciones y derechos personales. Lima: Gaceta Jurídica, 1999.

Vide, Osterling Parodi, Felipe y Castillo Freyre, Mario. Tratado de las Obligaciones. Tomo IV. Págs. 28 y 29.

3 Ibidem. Págs. 29, 30 y 31.

4 Vide, Osterling Parodi, Felipe y Castillo Freyre, Mario. Sus comentarios al artículo $1333^{\circ}$ del Código Civil. En: Código Civil Comentado. Tomo VI. Págs. 1000 y ss.

Tratado de Derecho Civil. Tomo III. Págs. 248 y 249.

Vide, del autor. El Acto Jurídico. Págs. 449 y ss.

Vide, del autor. El Acto Jurídico. Págs. 421 y ss.

Vide. Montoya Manfredi, Ulises. Comentarios a la Ley de Títulos Valores. Págs. 359 y ss.

Vide. El comentario de Giovanni Priori Posada. En: Código Civil Comentado. Tomo VI. Págs. 446 y ss.
} 